\title{
Development of innovative technologies as a reserve of competitiveness of reclamation enterprises
}

\author{
Irina Yurchenko ${ }^{1 *}$, Mikhail Bandurin ${ }^{2}$, and Inna Bandurina ${ }^{2}$ \\ ${ }^{1}$ All-Russia Research Institute of Hydraulic Engineering and Reclamation by the name of AN Kostyakov, 44, Bolshaya \\ Akademicheskaya st. Moscow, 127550, Russia \\ ${ }^{2}$ Kuban State Agrarian University named after I.T. Trubilin, 13, Kalinina st., Krasnodar, 350044, Russia
}

\begin{abstract}
Information support of production processes and production is becoming an unchangeable condition for their efficiency, in terms of importance comparable to the provision of material, technical, financial, labor and other resources. The paper is based on the methods of a systematic approach, analysis and synthesis of world trends in national and international theory and practice of interaction between digital technologies and business. It was found that innovations in the field of digital technologies for land reclamation do not meet the requirements of management automation implemented in the developed sectors of national and global economy. The factors of competitiveness of business processes, which are successfully integrated into management decisions using digital systems, are identified. The influence of managerial innovations on the strategic development of the business structures of an enterprise is characterized. In addition, the authors revealed the reasons for the unsatisfactory implementation of high-tech innovations by enterprises of traditional industries. The authors proposed the transfer of digital technologies from a high-tech sector of production to a low-tech one as a priority measure, representing the important condition for the growth of competitiveness of both traditional and high-tech sectors of economy.
\end{abstract}

\section{Introduction}

Recently, the informatization of production is considered as a priority approach to ensure the competitiveness of Russian economy, as a guarantor of the effectiveness of business processes of economic activity subjects (organizations, integrated structures, etc.) [1]. The program "Digital Economy of the Russian Federation", approved by the order of the Government on July 28, 2017 N 1632-r, sets the tasks and timeframes for the implementation of measures to support the development of efficient production in Russia by the state on the basis of complex application of highly integrated computer technologies, automation, "Digital twins", digital modeling and information processing at all stages of planning, development, quality assurance of production, operation up to disposal i.e. the entire life period of a product. The use of these approaches is planned for greater availability of public and commercial services, reduction of the cost of goods and products promotion, optimization of the time of payments and creation of alternative sources of income [2]. The purpose of this paper is to substantiate the principles of formation of digital information systems and mechanisms of functioning of digital information technologies in business processes of economic units of water reclamation complex in order to increase its competitiveness [3]. The relevance of the research is explained by the lack of a proper theoretical and methodological basis in the field of land reclamation to solve these issues, despite their exceptional importance, as well as the contradictory assessments of the effectiveness of the relationship between business strategy and digital methods.

\section{Materials and methods}

The purpose of the study is to form the principles of the creation of innovative systems and conditions for successful functioning of information technologies in the business processes of enterprises of reclamation water complex, contributing to its competitiveness and, as a consequence, viability [4]. During this study the following basic methods are used: a systematic approach, analysis, synthesis, as well as generalization of global trends, national and international theory and practice of interaction between digital technologies and business, contributing to the competitiveness of enterprises, especially those belonging to traditional sectors of economy, including agricultural production and reclamation. The sources of information were presented by the works of scientific and practical conferences, meetings and seminars, periodicals, the

* Corresponding author: chepura@mail.ru 
Internet [5] and data from state statistics bodies. In the modern realities of the evolution of market economy, the most important reserve of enterprise competitiveness, along with material-technical, financial, labor and other resources, is information, the timing, completeness and reliability of which determines the effectiveness of control actions at the horizontal and vertical levels of the functioning of production units. The formation of information for the organization of production of highquality and profitable products (services) [6] is performed by the digital system of an enterprise, which integrates the members of the production process in a single information field and provides controlled access to information about products, materials and production [7]. The increasing market requirements for the properties of supplied products, the introduction of the Internet into the infrastructure of digital systems leads to the transformation of the methods of production, which makes it necessary to automate not isolated functions, but to carry out comprehensive and integrated automation of processes that determine the competitiveness of an enterprise and products supplied to the market. It is necessary to note that the digital infrastructure in the field of reclamation does not correspond to the level of automation of management and the growth of the field of application of digital systems achieved in the developed sectors of the economy of a country [8]. Initially, the development of digital methods was focused on the automation of investment projects for reclamation and was aimed at the formation of an exclusively digital fund, implemented in the format of models of design objects and special applications that ensure the solution of the problems of creation and operation of a designed object. Design automation in the reclamation sector of economy began in the $60 \mathrm{~s}$ of the $20^{\text {th }}$ century [9]. First of all, the mechanization of sampling processes was carried out, requiring numerous arithmetic calculations and a small number of analytical dependencies and algorithms. The next step is the automated solution of target tasks that establish the design differences and parameters of the designed water reclamation management complex.

In the late 70 s and early 80 s of the $20^{\text {th }}$ century, the creation of software products for assessing the filtration and water-salt conditions of irrigated lands, calculations of drainage, predicting the evolution of agricultural production and the consumption of the most important natural resources (water and land) increased [10].

Since the mid-70s, the implementation of computeraided design systems based on design production lines for the functional structures of the designed reclamation facility has prevailed in the amelioration sector of economy. By the beginning of the reforms of Russian economy in the 90 s of the $20^{\text {th }}$ century, more than 350 CAD systems and (according to the estimates of experts) and more than 200 specialized programs were operating in design institutes, intended mainly to automate the design process of reclamation facilities.

\section{Results and discussion}

The changes in the domestic economic mechanism such as cost accounting, self-financing, self-sufficiency and the emergence of the market - determined both a decrease in design volumes and a lack of demand for CAD. Designers, providing savings in the salary fund, stopped performing specific automation work. In addition to the decline in the quality of the project due to the refusal of the required consideration of possible options and the disruption of the production design process, the lack of demand led to an almost complete loss of the "digital heritage" of reclamation [11]. The modern time, characterized by new "ecological thinking" of society and the transformation of the political and economic infrastructure of production, requires the creation of innovative digital technologies with the involvement of creative directions in methodology, mathematical models and methods of modeling, effective technologies, equipment and means of communication [12].

Today in reclamation enterprises there is a need for a class of modern management systems that provide decision support - Decision Support Systems (DSSs). There is a positive trend in the creation, implementation and use of digital technologies in reclamation production, which is proved by [13]:

- the periodic rotation of computers, equipment and means of information and communication links;

- the application of perfect commercial "digital office" programs [14];

- the organization of joint functioning of heterogeneous software products, technical platforms, communication networks, etc .;

- the priority of using control digital production systems, rather than digital information management systems;

- the adaptation of unified commercial digital systems of the enterprises of advanced economy sectors in the practice of reclamation [15].

However, the few digital technologies operating in reclamation enterprises are separated and implemented, for the most part, on the basis of various (analytical, statistical and technical) platforms for the automation of production subsystems, which reduces the effectiveness of managerial impact and increases production costs, which negatively affect competitiveness of both products and an enterprise as a whole.

The rapid development of digital technologies all over the world indicates the need for them by enterprises, but the ease of replication of digital technologies by competitors and the speed of the subsequent loss of the uniqueness of production create duality in the assessment of digital technologies as a factor in the competitiveness of an enterprise [16].

At the same time, the importance of the role of new information and knowledge of intra-production processes is obvious along with the policies of 
competitors and suppliers of material and technical resources, consumer requests, state tasks and actions of international organizations and other economic conditions in the competitiveness of enterprises [17]. In the case of a loss of the obtained advantages due to the corresponding reaction of competitors, an enterprise does not decrease the level of efficiency of business processes and it remains possible to operate within the framework of the occupied sphere and the established positioning.

In order to get an information resource, the following are used: software for control, accounting and analysis of production and management operations; document management systems, databases of industry organizations, government and corporate portals, websites and other sources of competitors that predetermine the separation and fragmentation of the initial data. The level of efficiency of business process directly depends on the automation of the processes of systematization of separated and fragmented information of various formats into a single information space and the management of this space, which gives reasons to attribute digital technologies to the factors of enterprise competitiveness.

According to the analysis, the effective factors of the competitiveness of an economic entity that are successfully implemented with the support of management decisions by digital systems formed on the basis of digital technologies include [18]:

- the reduction of the cost of production (services) release processes;

- the improvement of consumer properties of products based on the transformation of design and technological solutions;

- the expansion of sales markets;

- the optimization of the period of renewal of products supplied to the market;

- the efficiency of strategic, tactical and day-to-day planning;

- the strict accounting and consistent actions to transform consumer demand;

- the improvement of logistics services;

- the regulation of the composition and structure of workflow and information flows [19];

- the increase in the effectiveness of intra-production coordination of impacts and regulation of production;

- the increase in labor productivity with its automation and the absence of routine.

It is obvious that the capabilities of digital systems that guarantee the competitiveness of a company largely depend on the quality and availability of information, the qualifications of users and the motivation of personnel to improve business processes that affect the efficiency of the use of analytical information. As the strategic importance of technology for market competition decreases, the role of skills in its daily use can become decisive in the success of an enterprise [20].

The competitiveness of the digital systems themselves is provided by:

- the integrity, due to the scientific and methodological substantiation of the principles of creation and evolution;

- the interrelation of digital funds and their regulation operations, which increase the effectiveness of the organization's coordination;

- the use of unified digital technologies for data transformation and transfer;

- the use of uniform standards for data accumulation, complied with the global ones, contributing to the unification of information flows;

- the modular nature of development, openness and flexibility of architecture, realizing the possibility of constant growth and evolution;

- the high level of integration of specialized programs and automation of information procedures and operations of the functional structures of a company, taking into account the balance of production processes and operations;

- the large volumes of processed data, the speed of their transformation and exchange;

- the degree of accuracy, relevance and security of information about the production operations and products of a company in technological lines;

- the effectiveness of communication, both between structural formations and members of the technological line.

- the information security, authorization and control of access to information;

- the presence of professional specialists interconnected with the main activities of a company, specially trained for the operation of high-tech digital systems.

The unsatisfactory solution to these issues leads to the deviations from the timing of the implementation of planned activities, increase in production costs, loss of consumer properties of products and negative phenomena resulting in the loss of the effectiveness of business processes.

One of the possible ways to improve the processability of digital systems in traditional production sectors can be their transfer from high-tech sectors [21]. At the same time, the increase in the level of competitiveness in the traditional production sector is ensured and caused by innovative transformations. A main condition for the feasibility of such a transfer is the readiness of an enterprise in the traditional sector of economy to introduce innovations. For high-tech sectors of economy, the impact of the degree of interconnections with traditional industries on competitiveness is 
explained by the level of demand for innovative technologies in enterprises of low-tech industries.

It is obvious that each individual company makes its own choice of innovative development, which is based on a thorough analysis of its needs, taking into account real situations and individual preferences. However, it seems correct not to forget about the "classical" approach to the solution of this problem, formulated by the researcher of the impact of digital technologies on the competitiveness of business processes, Nicholas J. Carr: "spend less; follow the leader, do not rush forward; innovate if the risks are negligible; think about shortcomings, not about opportunities "[5].

In the domestic practice of reclamation, the existing volumes of investment in high-tech automation systems, in fact, deprive the organization of the possibility of fullscale implementation of digital methods. The existing high degree of wear and obsolescence of equipment and structures of the reclamation water management complex impedes the implementation of innovative digital methods of production regulation. Consequently, each digital technology is seen as an addition to traditional control.

In the modern state of the economy of Russia, the evolution of innovation processes in the dominant sector of traditional production can be carried out by the supply from high-tech sectors, which will become a source of dynamic growth of Russian economy as a whole. This aspect transfers the problem of the formation of digital economy in traditional production sectors to the state level and does not contribute to the growth of optimism about its early and favorable solution. However, the experience of overcoming difficulties through the examples of the development of informatization of the country, in general, and the reclamation sector of production, in particular, gives confidence in the reality of a successful solution of this problem.

\section{Conclusion}

The use of information digital system in the practice of regulation of production reduces the cost of management processes and improves consumer properties of products, thereby increasing the competitiveness of a company.

Digital technologies, performing the functions of a link between separate fragmentary information, knowledge, data within a company, industry and government structures, represent the basis for innovations that combine high technologies with traditional goods and services. This provides a supplied product with new properties that are potentially inaccessible to enterprises in the traditional industry without transfer of innovations from high-tech sectors of economy.

\section{References}

1. H. Hirsch-Kreinsen Chelteham (UK, Edward Elgar Publishing Limited, 2014)
2. I. V. Bogachev Forum Cnews Transcript of the speech on November 14, 2013 Moscow (2013)

3. M. A. Bandurin, I. F. Yurchenko, I. P. Bandurina International MultiConference on Industrial Engineering and Modern Technologies, Far East Conference 2019, 8933970 (2019)

4. M. Jeffrey Data driven marketing. 15 indicators that everyone should know (Moscow, Mann, Ivanov and Ferber, 2013)

5. J. Carr Publishing house Secret of the firm (2005)

6. D. A. Markov Izvestiya of the Russian State Pedagogical University. A.I. Herzen 12(90) (2009)

7. F. K. Abdrazakov, S. S. Orlova, T. A. Pankova, E. N. Mirkina, O. V. Mikheeva Journal of Interdisciplinary Research 8(1) 154-161 (2018)

8. S. Vladimirov, I. Prikhodka, T. Safronova, E. Chebanova E3S Web of Conferences 17512010 (2020)

9. L. V. Kireicheva, N. P. Karpenko Eurasian soil science 48(5) 524-532 (2015)

10. Report "Digital Russia: New Reality" (2017)

11. M. Porter Competition (M: Ed. House "Williams", 2003)

12. V. I. Olgarenko, G. V. Olgarenko, I. V. Olgarenko Melioration and water management 6 8-11 (2013)

13. V.I. Olgarenko, I.V. Olgarenko, V.I. Olgarenko IOP Conference Series: Materials Science and Engineering, 698(2) (2019)

14. B. P. Chesnokov, O. V. Naumova, V. A. Strelnikov, F. K. Abdrazakov, B. A. Tronin International Journal of Applied Engineering Research, 11 2140-2144 (2016)

15. L. V. Kireicheva, O. A. Zakharova Eurasian Soil Science, 35(9) 990-995 (2002)

16. M. A. Bandurin, V. A. Volosukhin, V. V. Vanzha,; A. V. Mikheyev, Y. V. Volosukhin Aer-advances in engineering research 157 70-75 (2018) 
17. T. Jaegers Eurostat Statistics in focus (2013)

18. Vater Hendrick, Bail Elena. HaufeLexware mbH\&Co (2013)

19. P. Watson, N. Chileshe, D. Maslow A Construction Industry Development 2nd Postgraduate Conference -Cape Town South Africa 129-141 (2004)

20. M. A. Bandurin, V. A. Volosukhin, A. V. Mikheev, Y. V. Volosukhin, I. P. Bandurina International conference on mechanical engineering, automation and control systems 327 (2017)

21. D.V. Kozlov Water Resources, 28(2) 215-219 (2001) 